\title{
Training Need Assessment Among Health Care Providers in Public Health Facilities of Benishangul Regional State, North West Ethiopia, 2018
}

\author{
Lemessa Jira $^{1}$, Nigatu Weyessa ${ }^{1}$, Sileshi Mulatu ${ }^{1}$, Tamiru Bogale ${ }^{2}$ \\ ${ }^{1}$ Department of Nursing, Pawe Health Science College, Pawe, Ethiopia \\ ${ }^{2}$ Department of Paediatrics and Child Health Nursing, College of Medicine and Health Sciences, Bahir Dar University, Bahir-Dar, Ethiopia
}

\section{Email address:}

lemessa21@gmail.com (L. Jira),nigatuwey@gmail.com (N. Weyessa), silshimulatu@gmail.com (S. Mulatu), tamiru_bogale@yahoo.com (T. Bogale)

\section{To cite this article:}

Lemessa Jira, Nigatu Weyessa, Sileshi Mulatu, Tamiru Bogale. Training Need Assessment Among Health Care Providers in Public Health Facilities of Benishangul Regional State, North West Ethiopia, 2018. American Journal of Life Sciences. Vol. 8, No. 5, 2020 , pp. 114-120. doi: $10.11648 /$ j.ajls.20200805.15

Received: May 8, 2020; Accepted: May 22, 2020; Published: August 27, 2020

\begin{abstract}
Background: Continuing education is crucial for quality improvement in health care. The needs assessment of CE helps to ensure effectiveness. However, such an assessment necessitates certain techniques that are unfamiliar to health care communities in developing countries. This study identifies the needs of providing training to health care providers in Benishangul Gumuz regional sate. Objective: The aim of this survey is to assess training needs among health care providers in Benishangul Gumuz regional state health facility, North West Ethiopia, 2018 Methods: An institution based cross-sectional study was conducted from Jun first to July 30, 2018 in public health facilities of Benishangul Gumuz regional state. This study was designed as a questionnaire survey to investigate the demographics, training needs, and preferred approaches to improve performance of the target population. The study population included the health care providers of public health care facilities in Benishangul Gumuz regional sate. We used the World Health Organization- adopted Hennessy Hicks Training Needs Analysis Questionnaire, a self-reported close-ended structured questionnaire with a core set of 30 items. Results: In total, 450 questionnaires were distributed; the response rate was $86 \%$, and most respondents were nurses. Neonatal care, Gender based violence, Emergency care, Maternal care, Public health promotion /Disease prevention/, TB /Leprosy, Malaria, ART, Treatment of intensive care patients (ICU) and Leadership and system thinking was found to be the most required training needs among health care providers in the public health facilities of Benishangul Gumuz regional state Conclusions: Providing training according to needs is vital, particularly in developing countries like Ethiopia where resources are extremely limited. The assessment result offers perspective on how to conduct needs assessment and serve as a reference for the region. Planning to provide training to health care providers particularly on Neonatal care, Gender based violence and Emergency care take a priority for the region.
\end{abstract}

Keywords: Continuing Education, Continuing Professional Education, Training Needs Assessment

\section{Background}

Training Need Assessment (TNA) is defined as an investigation, undertaken to determine the nature of performance problems in order to establish the underlying causes and the way in training can address the gap. It is recognized as the first step in any Human Resource Development intervention in any organization. Training needs come from under developed skills, insufficient knowledge or inappropriate worker attitudes. The assessment begins with a "need" which can be identified in several ways but is generally described as a gap between what is currently in place and what is needed, now and in the future [1-3]

Any need assessment must address three key areas: the organization, the job and the individual. Organizational level 
considers the proposed training within the context of the rest of the organizations within it.

Training is an important activity within an organization and it aimed at effecting positive changes in the trainees in terms of their knowledge, skills and attitudes, and making the level of performance better. By its nature, Training Needs Assessment refers to the organizational process of collecting and analyzing data that supports decision making about when training is the best option or not to improve individuals' performances, define who should be trained, and exactly what content should be taught [1, 4-6]

Despite its importance, research shows that training needs assessment has been done in an unsystematic manner in organizational settings of the developing countries. Training is often provided without much planning which happens in developing countries including Ethiopia. In Management, studies lack systematic theoretical and methodological approaches which may provide consistency to training need assessment research and practices [7-9]

Continuing education (CE) is crucial for quality improvement in health care. However, CE is often provided without much planning, which happens in developing countries. A needs assessment of $\mathrm{CE}$ of all the involved parties is crucial to ensure $\mathrm{CE}$ effectiveness. Health care professionals in low-resource countries oftentimes do not have the obligation to demonstrate ongoing education or competence; Past research had found low levels of provider training and huge quality gaps in less developed countries [10-12]

As world health organization (WHO, 2007) recommendations, the health workforce is one of the six building blocks of the health-care system if countries need to strengthen the objective of universal equitable access to good quality health services is to be achieved. A difficult environment and many challenges still remain to achieve Health care provider capacity building successfully.

Ambivalent political will, as well as hostility of health care provider towards other community stakeholders compromised participation and accountability in delivering their role and responsibility, especially in relation to their roles in decision-making. Other problems like: lack of information; poor knowledge of the legal framework; lack of adequate skill; lack of motivation and inadequate positive attitude are also remain as a difficulties in achieving competent health care provider [13-15].

This study identified the needs of providing CE to health care personnel in Benishangul Gumuz regional state. The results are expected to provide insight to policy makers, financers, and health care organizations for guiding training planning and funding allocation required for continuing professional education. In addition, this study offered perspectives on how to conduct training needs assessment and serves as a reference for developing countries whose environments are similar to that of Benishangul Gumuz regional state.
In Benishangul Gumuz regional state, training need assessment is not done yet to produce scientific evidence to plan future training need in the region for short term and long term training at the regional and organizational level. Therefore Training need assessment at regional level was conducted to improve the quality of health care by improving health care provider performance.

\section{Methods and Materials}

Institution based study was conducted from Jun to July $30 / 2018$ in public health facilities of Benishangul Gumuz regional state. Benishangul-Gumuz Regional State is one of the nine regional states of the federal democratic republic of Ethiopia. The capital city of the region, Assossa is $675 \mathrm{~km}$ far from Addis Ababa to the North West. The region is administratively composed of 3 zones, 20 woreda (with one of the special woreda) and 470 Kebeles. The region shares common borders with the state of Amhara in the East, the Sudan in the North-East, and the state of Oromia in the South.

The region has a total area of approximately $50,380 \mathrm{~km}^{2}$ with altitude ranging from 580 to 2,731 meters above sea level. The population size of the region is estimated at $1,000,000$ and the proportion of male and female is $50.7 \%$ and $49.3 \%$ respectively.

The annual population growth rate is estimated at 3\% per annum. About $13.5 \%$ and $86.5 \%$ of the population are living in urban and rural areas respectively.

According to 2010 EFY regional health Bauru there are Two general hospitals, four primary hospitals (Two of them are nonfunctional) 45 health centers and 402 health posts.

The regional health system is staffed with 3766 health care providers including health extension workers. Among this there are 5 specialist; 47 general practitioner; 210 health officer; 222 BSc nurse; 1043 diploma nurse; 165 BSc midwife, 242 diploma midwife, 52 laboratory technologist, 92 laboratory technician, 56 pharmacist, 149 pharmacy technician and 57 environmental health professionals.

\subsection{Study Design}

Institution based cross-sectional study design was conducted.

\subsection{Source Population}

The source population was all health care providers working as staff in public health facilities of Benishangul Gumuz regional state.

\subsection{Study Population}

The study populations was all health care providers those actively working in selected public health facilities of Benishangul Gumuz regional state during data collection period. 


\subsection{Study Variables}

1) Socio demography

2) Short term training

3) Long term training

\subsection{Inclusion and Exclusion Criteria}

\subsubsection{Inclusion Criteria}

Employed health care provider staff working in public health facilities of Benishangul Gumuz regional state and available during study period will be included in the study.

\subsubsection{Exclusion Criteria}

Health care provider who is on annual leave and maternal leave during data collection period was excluded from the study.

\subsection{Sample Size Determination and Sampling Procedure}

Since there is no similar study conducted in this topic so that we use $50 \%$ proportion, so the preferred sample size determination method is single population proportion with estimation of $95 \%$ level of confidence and maximum tolerable error $5 \%$.

$$
\mathrm{n}=(\mathrm{Z} \alpha / 2)^{2} \mathrm{p}(1-\mathrm{p}) / \mathrm{d}^{2}
$$

Where $\mathrm{Z}=$ Standard normal distribution of $95 \%$

$\mathrm{P}=$ population proportion $(50 \%)$

$\mathrm{d}=$ margin of error $(5 \%)$,

$1.96^{2} * 0.5(1-0.5)^{2} / 0.05^{2}=384$, by adding $10 \%$ non-response rate our sample size was 423 .

Purposive cluster sampling technique was employed to select the public health facilities in the region. All health care providers in the selected public health facilities was participated during data collection.

\section{Results}

Socio-demographic Characteristics

A total of 383 health care workers participated in the study with $90.54 \%$ response rate. Out of total participants 211 (55.1\%) were males, age of the participants included in range of 20 to 45 with mean age of $29(\mathrm{SD}= \pm 4.91)$ years. Accordingly, most respondents in this study were $229(60 \%)$ married and 144 (37.6\%) single.

Regarding Profession, most respondents were nurses, 173 (45.2\%). 38 (15.8\%), pharmacy $53(13.8 \%)$ midwifery 55 $(14.4 \%)$ and laboratory $36(9.4 \%)$ and $143(37.3 \%)$ participants had 1 to 6 year work experience and among respondents $275(71.8 \%)$ had not taken any additional education but $91(23.8 \%)$ had taken additional education which is relevant to their profession.

A considerable number of respondents were not at any management or supervisory position at the time of the survey 297 (77.5\%). Among surveyed health care professionals, 228 $(59.5 \%)$ had undergone previous work-related training; of these, $130(33.9 \%)$ of them had undergone more than 2 sessions.
Table 1. Socio demographic characteristics of health care providers in public hospitals of Benishangul Gumuz regional state Western, Ethiopia, August 2018.

\begin{tabular}{|c|c|c|c|}
\hline Variable & & $\begin{array}{l}\text { Frequency } \\
(n=383)\end{array}$ & $\begin{array}{l}\text { Percent } \\
(\%)\end{array}$ \\
\hline \multirow{3}{*}{ Sex } & Male & 211 & 55.1 \\
\hline & Female & 172 & 44.9 \\
\hline & $<=28$ years & 218 & 57.0 \\
\hline \multirow[t]{3}{*}{ Age } & 29-39 years & 147 & 39.0 \\
\hline & $>=40$ years & 18 & 4.0 \\
\hline & Married & 229 & 59.8 \\
\hline \multirow[t]{4}{*}{ Marital states } & Single & 144 & 37.6 \\
\hline & Divorced & 10 & 2.6 \\
\hline & Certificate & 13 & 3.4 \\
\hline & Diploma & 190 & 49.6 \\
\hline \multirow[t]{4}{*}{ Qualification } & Bachelor degree & 165 & 43.1 \\
\hline & Master's degree & 10 & 2.6 \\
\hline & Other & 5 & 1.3 \\
\hline & $<1$ year & 51 & 13.3 \\
\hline \multirow{5}{*}{ Experience } & 1-6 year & 230 & 60 \\
\hline & 7-9 year & 44 & 11.5 \\
\hline & $\geq 10$ years & 58 & 15.14 \\
\hline & Physician & 38 & 9.9 \\
\hline & Pharmacist & 53 & 13.8 \\
\hline \multirow{4}{*}{ Profession } & Laboratory & 36 & 9.4 \\
\hline & Nurse & 173 & 45.2 \\
\hline & Midwifery & 55 & 14.4 \\
\hline & Other & 25 & 6.5 \\
\hline \multirow{3}{*}{ Upgrade } & Yes & 94 & 24.6 \\
\hline & No & 289 & 75.4 \\
\hline & Lack of motivation & 27 & 9.3 \\
\hline \multirow{4}{*}{$\begin{array}{l}\text { Reason for } \\
\text { delays }\end{array}$} & Family responsibilities & 48 & 16.6 \\
\hline & Financial problem & 32 & 11 \\
\hline & Lack of sponsor & 157 & 54.3 \\
\hline & Other & 25 & 8.6 \\
\hline \multirow{4}{*}{ Relevance } & Relevant & 60 & 63.8 \\
\hline & Not relevant & 10 & 10.6 \\
\hline & Somewhat relevant & 24 & 25.5 \\
\hline & General hospitals & 178 & 46.5 \\
\hline \multirow[t]{2}{*}{ Work Place } & District hospitals & 17 & 4.4 \\
\hline & Primary health center & 188 & 49 \\
\hline \multirow{2}{*}{$\begin{array}{l}\text { Work-related } \\
\text { training }\end{array}$} & Yes & 228 & 59.5 \\
\hline & No & 155 & 40.5 \\
\hline \multirow{4}{*}{$\begin{array}{l}\text { Number of } \\
\text { Training } \\
\text { session }\end{array}$} & One & 130 & 57 \\
\hline & Two & 74 & 32.4 \\
\hline & Three & 21 & 9.2 \\
\hline & Above three & 3 & 1.3 \\
\hline \multirow{2}{*}{$\begin{array}{l}\text { Managerial } \\
\text { position }\end{array}$} & Yes & 86 & 22.5 \\
\hline & No & 297 & 77.5 \\
\hline
\end{tabular}

Short Term Training

As table two shows, thirty training area was provided for the health care provider respondent to express their area of training need as not important, neutral and important to their current job in the health facilities for each training area independently. Based on the respondents preference; Neonatal care, Gender based violence, Emergency care, Maternal care, Public health promotion /Disease prevention/, TB /Leprosy, Malaria, ART, Treatment of intensive care (ICU), and Leadership and system thinking was found to be 
the most required training areas among health care providers in the public health facilities of the region.

The most top three required area of training need among thirty training tittle chosen by the respondent as important for their current job were Neonatal care, 318 (83\%), Gender based violence $316(82.5 \%)$ and Emergency care, 315 $(82.2 \%)$ respectively (Table 2$)$.

Table 2. Expressed short term training need of respondents in public health facilities of Benishangul Gumuz regional state North West Ethiopia, August /2018 $(N=383)$.

\begin{tabular}{|c|c|c|c|}
\hline Skill area & Not important & Important & Neutral \\
\hline 1) Clinical skills & $19(5 \%)$ & $56(14.6 \%)$ & $308(80.4 \%)$ \\
\hline 2) Proper documentation & $31(8.1 \%)$ & $282(73.6 \%)$ & $70(18.3 \%)$ \\
\hline 3) Public health promotion /Disease prevention/ & $18(4.7 \%)$ & $309(80.7 \%)$ & $56(14.6 \%)$ \\
\hline 4) Use of medical equipment & $31(8.1 \%)$ & $266(69.5 \%)$ & $86(22.5 \%)$ \\
\hline 5) Disaster management & $44(11.5 \%)$ & $222(58 \%)$ & $117(30.5 \%)$ \\
\hline 6) Health information management & $29(7.6 \%)$ & $270(70.5 \%)$ & $84(21.9 \%)$ \\
\hline 8) Communication skills & $30(7.8 \%)$ & $267(69.7 \%)$ & $86(22.5 \%)$ \\
\hline 9) Palliative care & $36(9.4 \%)$ & $244(63.7 \%)$ & $103(26.9 \%)$ \\
\hline 10)Culturally competence skill & $31(8.1 \%)$ & $230(60.1 \%)$ & $122(31.9 \%)$ \\
\hline 11)Administrative, Supervisory or Management & $26(6.8 \%)$ & $257(67.1 \%)$ & $100(26.1 \%)$ \\
\hline 12)Gender based violence & $16(4.2 \%)$ & $316(82.5 \%)$ & $51(13.3 \%)$ \\
\hline 13)Neonatal care & $17(4.5 \%)$ & $318(83 \%)$ & $48(12.5 \%)$ \\
\hline 15)Computer skills & $16(4.2 \%)$ & $296(77.3 \%)$ & $71(18.5 \%)$ \\
\hline 16)Leadership and system thinking & $20(5.2 \%)$ & $271(70.8 \%)$ & $92(24 \%)$ \\
\hline 17)Emergency care & $21(5.8 \%)$ & $315(82.2 \%)$ & $47(12.3 \%)$ \\
\hline 18)Treatment of intensive care patients & $22(5.7 \%)$ & $292(76.2 \%)$ & $69(18 \%)$ \\
\hline 19)Quality improvement assurance & $14(3.7 \%)$ & $292(76.2 \%)$ & $77(20.1 \%)$ \\
\hline 20)Program planning skill & $18(4.7 \%)$ & $271(70.8 \%)$ & $94(24.5 \%)$ \\
\hline 21)Counseling & $15(3.9 \%)$ & $267(69.7 \%)$ & $101(26.4 \%)$ \\
\hline 22)Treatment of patients with mental health needs & $22(5.7 \%)$ & $268(70 \%)$ & $93(24.3 \%)$ \\
\hline 23)Clinical laboratory skill & $37(9.7 \%)$ & $231(60.3 \%)$ & $115(30 \%)$ \\
\hline 24)TB /Leprosy & $19(5 \%)$ & $306(79.9 \%)$ & $58(15.1 \%)$ \\
\hline 25)ART & $16(4.2 \%)$ & $304(79.4 \%)$ & $63(16.4 \%)$ \\
\hline 26)Malaria & $21(5.5 \%)$ & $296(77.3 \%)$ & $66(17.2 \%)$ \\
\hline 27)Logistic system (IPLS) & $19(5 \%)$ & $292(76.2 \%)$ & $72(18.8 \%)$ \\
\hline 28)Auditable pharmaceutical transaction and service (APTS) & $33(8.6 \%)$ & $241(62.9 \%)$ & $109(28.5 \%)$ \\
\hline
\end{tabular}

Table 3. Ten prioritized training need of need of respondents in public health facilities of Benishangul Gumuz regional state North West Ethiopia, August /2018 $(N=383)$.

\begin{tabular}{|c|c|c|c|}
\hline Training title/training area & Not important & Important & Neutral \\
\hline 1) Neonatal care & $17(4.5 \%)$ & $318(83 \%)$ & $48(12.5 \%)$ \\
\hline 2) Gender based violence & $16(4.2 \%)$ & $316(82.5 \%)$ & $51(13.3 \%)$ \\
\hline 3) Emergency care & $21(5.8 \%)$ & $315(82.2 \%)$ & $47(12.3 \%)$ \\
\hline 4) Maternal care & $11(2.9 \%)$ & $311(81.2 \%)$ & $61(15.9 \%)$ \\
\hline 5) Public health promotion /Disease prevention/ & $18(4.7 \%)$ & $309(80.7 \%)$ & $56(14.6 \%)$ \\
\hline 6) $\mathrm{TB} /$ Leprosy & $19(5 \%)$ & $306(79.9 \%)$ & $58(15.1 \%)$ \\
\hline 7) Antiretroviral therapy (ART) & $16(4.2 \%)$ & $304(79.4 \%)$ & $63(16.4 \%)$ \\
\hline 8) Malaria & $21(5.5 \%)$ & $296(77.3 \%)$ & $66(17.2 \%)$ \\
\hline 9) Treatment of intensive care patients (ICU) & $22(5.7 \%)$ & $292(76.2 \%)$ & $69(18 \%)$ \\
\hline 10)Leadership and system thinking & $20(5.2 \%)$ & $271(70.8 \%)$ & $92(24 \%)$ \\
\hline
\end{tabular}

Based on the respondents preference; Neonatal care (82.5\%), Emergency care $(81.2 \%)$, Maternal care (80.7\%), Public health promotion /Disease prevention/(80\%), Treatment of intensive care (ICU) (77\%) was found to be the most required long training areas among health care providers in the public health facilities of the region. (Figure 1) 


\section{Long and Short training need among health care providers}



Figure 1. Frequency distribution by respondent's short term and long term training profile in the public facilities of Benishangul Gumuz regional state, 2018.

\section{Long Term Training}

Most health care providers, 289 (75.4\%) have not make their next educational career after initial qualification throughout their work experience. While 94 (24.6\%) have make their next educational career after initial qualification throughout their work experience among this only 24 $(24.6 \%)$ of the respondents was made their educational career and most of which, $60(63.38 \%)$ was relevant to their current job in their health facilities. The reason of most respondents, $157(54.3 \%)$ for not making their next educational career was financial problem. While only $25(8.6 \%)$ of respondent's reason for not making their next educational career was lack of government sponsor, (Figure 2)

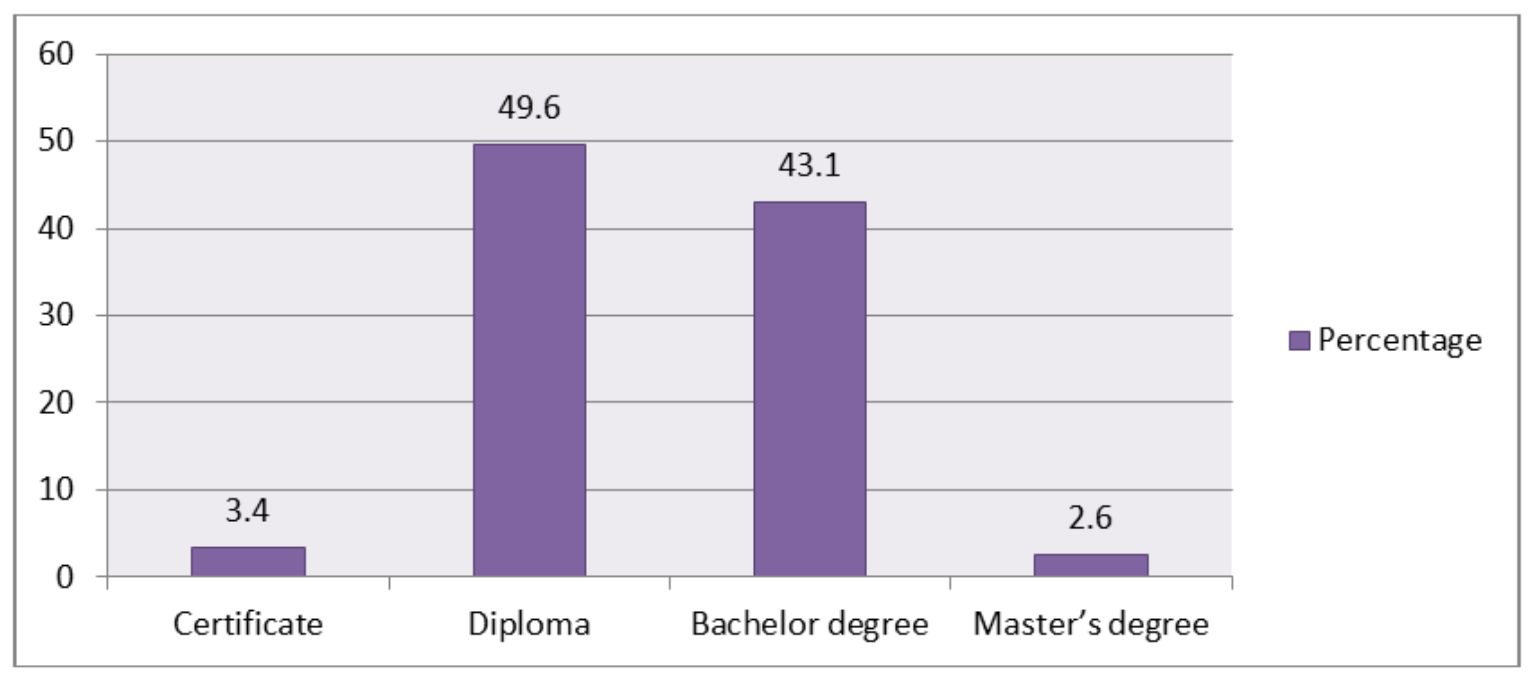

Figure 2. The percentage distribution of level of education among health care workers in public health facilities of Benishangul Gumuz regional state $(n=383)$. 


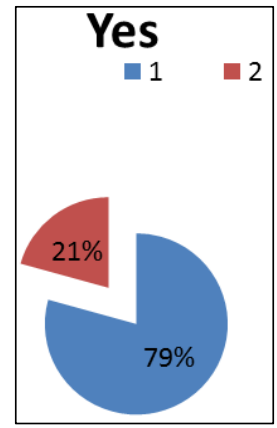

Figure 3. The percentage distribution of Work-related training among health care workers in Benishangul Gumuz regional state ( $n=383)$.

\section{Discussion}

It is not entirely clear how a health care professional would determine which tasks are crucial and how well they perceive their actual performance of that task to determine the need. However, these may be influenced by several factors, including their motivation to continue learning, a special interest in that particular task, an encounter or deficiency in their previous education, and their satisfaction or dissatisfaction with the management of the department among others. The finding of this study show the training gaps of the health care provider in the region.

In all, 383 health care providers were participated with the response rate of $86 \%$, which was satisfactory when compared with the rates reported in similar studies on health care professionals that used the same tool [16-19]. Most respondents in this study were females and most respondents belonged to the 29- 39 years age group, as was the case in related studies [18]. Younger professionals were found to require more training than did professionals from other age groups. This finding is consistent with those of other studies that suggest that the younger generation typically has higher career aspirations and is therefore more likely to undertake further training. Most respondents have a need to attending long term training programs with respective of their profession for further professional growth. An equal number of respondents (60\%) had 1-6 years and more than 6 years of work experience; thus, these two groups formed the majority when the respondents were classified by seniority. Despite this considerable service years of health care providers, more than $50 \%$ of health care providers had diploma and below educational qualifications in varies health disciplines.

The respondents indicated various needs in the section of the questionnaire that had options on needs they considered necessary. Neonatal care, Gender based violence, Emergency care, Maternal care, Public health promotion /Disease prevention/, TB /Leprosy, Malaria, ART, Treatment of intensive care patients (ICU) and Leadership and system thinking, among others, were the most commonly reported needs. Most respondents required clinical skill training and training associated with the department in which they worked. This suggests that they would prefer any type of training that concentrates on the current advanced practices in the department they have been assigned.

Clear and appropriate communication and interdisciplinary collaboration is critical for delivering quality care for complex clinical setting in the present health care settings $[20,21]$. Collaborative practice among all health care professionals creates a positive work environment. Poor communication and a lack of teamwork or collaboration have been persistent problems in health care.

A considerable number of respondents were not at any management or supervisory position at the time of the survey (77.5\%). Similar to any health care organization, the general staff outnumber the managerial staff. Most respondents worked for acute general hospitals. As anticipated, Victoria Hospital accounted for the highest number of respondents $(56.5 \%)$ because it is the largest health care facility in the country and employs the most health care personnel. Of the surveyed health care professionals, over $59.5 \%$ had undergone previous work-related training; of these, $32.4 \%$ of them had undergone more than 2 sessions this indicates that some level of training occurs at the institutions.

\section{Conclusion}

In this study, Neonatal care, Gender based violence, Emergency care, Maternal care, Public health promotion /Disease prevention/, TB /Leprosy, Malaria, ART, Treatment of intensive care (ICU), and Leadership and system thinking was found to be the most required training areas among health care personnel in the public health facilities of Benishangul Gumuz regional state. Neonatal care accounted for the biggest need. More than $50 \%$ of health care providers have diploma and below diploma educational qualifications. Providing training according to needs is vital, particularly in developing countries where resources are extremely limited. The present research methodology and findings also offer perspective on how to conduct needs assessment and serve as a reference for developing regions whose health care environments are similar to that in the region.

\section{List of Abbreviations}

APTS-Auditable pharmaceutical transaction and service

ART-Anti retroviral therapy

RHB-Regional health Beaurau

CE- Continuous education

HFs- Health facilities

ICU- Intensive care unite

TB-Tuberculosis

TNA- Training Need Assessment

WHO-World health organization

\section{Declarations}

\section{Ethics Approval and Consent to Participate}

Ethical approval obtained from the ethical review 
committee of school of nursing Bahir Dar University and pawe health Science College. Administrative permissions granted and confidentiality ensured using codes and keeping questionnaires locked. All respondents assured that the data would not have any negative consequence on any aspects of their life and participants who refused the consent respected

\section{Consent for Publication}

Not applicable

\section{Availability of Data and Material}

Additional file: Data abstraction tool

\section{Competing Interests}

The authors have declared that they have no competing interest.

\section{Authors' Contribution}

LJ: conception of the research idea, study design, data collection, analysis and interpretation, and manuscript writeup. NW, SM, TB: data analysis, interpretation, and supervision. LJ and SM: data collection, analysis and interpretation, and manuscript write-up. All authors have read and approved the final manuscript.

\section{Funding}

Not applicable.

\section{Acknowledgements}

The authors would like to acknowledge the pawe Health Sciences College and Benishangul Gumuz regional sate health office for financial support of this research project. The authors also extend their special thanks for both data collectors and supervisors.

\section{References}

[1] Government of St. Lucia Statistics Department. 2010 Population and Housing Census. Castries, Saint Lucia: Government of St. Lucia Statistics Department; 2010.

[2] Harmsen J, Ellis G, Deveaux R. A History of St. Lucia. Place Moule a Chique. Vieux Fort, St. Lucia: Lighthouse Road Publications; 2012.

[3] The World Fact Book. Available at https://www.cia.gov/library/publications/theworldfactbook/geos/st.html. Accessed 30 October 2013.

[4] Queeney DS. Assessing Needs in Continuing Education: An Essential Tool for Quality Improvement. San Francisco: Jossey-Bass; 1995.

[5] Griscti O, Jacono J. Effectiveness of continuing education programmes in nursing: literature review. J Adv Nurs. 2006; 55 (4): 449-56.
[6] Das J, Holla A, Das V, et al. In urban and rural India, a standardized patient study showed low levels of provider training and huge quality gaps. Health Aff. 2012; 31: 2774 84 .

[7] Haynes R, Johnson B, Springer C. Report of the Health Review Commission. Saint Lucia: Ministry of Health; 2004.

[8] Worthen BR, Sanders JR, Fitzpatrick JL. Program evaluation. Castries, Saint Lucia: Longman; 1997.

[9] Rossett A. Training needs assessment. Castries, Saint Lucia: Prentice Hall; 1987.

[10] Bartholomew LK, Parcel GS, Kok G. Intervention mapping: A process for developing theory and evidence-based health education programs. Health Educ Behav. 1998; 25 (5): 54563.

[11] Kaufman RA, English FW. Needs assessment. Concept and application. Castries, Saint Lucia: Educational Technology; 1979.

[12] Hicks C, Hennessy D. The use of a customized training needs analysis tool for nurse practitioner development. J Adv Nurs. 1997; 26 (2): 389-98.

[13] Hicks C, Hennessy D. Applying psychometric principles to the development of a training needs analysis questionnaire for use with health visitors, district and practice nurses. J Res Nurs. 1996; 1 (6): 442-54.

[14] Hicks C, Hennessy D. Hennessy-Hicks Training Needs Analysis Questionnaire and Manual. Available at: http://www.who.int/workforcealliance/knowledge/resou rces/hennessyhicks_trainingneedsquest/en/ Accessed 19 February 2016.

[15] Hicks C, Hennessy D, Cooper J, Barwell F. Investigating attitudes to research in primary health care teams. J Adv Nurs. 1996; 24 (5): 1033-41.

[16] Hennessy D, Hicks C. A Cross-Cultural Tool to Identify Continuing Education Needs. Int Nurs Rev. 1998; 45 (4): 109-14.

[17] Hicks C, Tyler C. Assessing the skills for family planning nurse prescribing: Development of a psychometrically sound training needs analysis instrument. J Adv Nurs. 2002; 37 (6): $518-31$.

[18] McCaughan D, Thompson C, Cullum N, Sheldon TA, Thompson DR. Acute care nurses' perceptions of barriers to using research information in clinical decision-making. J Adv Nurs. 2002; 39 (1): 46-58.

[19] Hicks C, Hennessy D. Quality in post-basic nurse education: The need for evidence-based provision. J Nurs Manag. 1999; 7 (4): 215-24.

[20] Rosenstein AH, O'Daniel M. Disruptive behavior and clinical outcomes: Perceptions of nurses and physicians. Am J Nurs. 2005; 105 (1): 54-65.

[21] Chastonay P, Moretti R, Zesiger V, Cremaschini M, Bailey R, Pariyo G, et al. Health workforce development: a needs assessment study in French speaking African countries. Adv Health Sci Educ Theory Pract. 2013; 18 (2): 265-77. Epub 2012/03/29. 